\title{
Systematic review of functional training on muscle strength, physical functioning, and activities of daily living in older adults
}

\author{
Chiung-ju Liu • Deepika M. Shiroy • Leah Y. Jones • \\ Daniel O. Clark
}

Received: 24 January 2014 / Accepted: 15 August 2014 / Published online: 30 August 2014

(C) European Group for Research into Elderly and Physical Activity (EGREPA) 2014

\begin{abstract}
Exercise programs are often recommended for preventing or delaying late-life disability. Programs that incorporate functional training, which uses movements similar to performing activities of daily living, may be suitable for such recommendation. The purpose of this systematic review was to examine the effects of functional training on muscle strength, physical functioning, and activities of daily living in older adults. Studies in three electronic databases (MEDLINE, CINAHL, and SPORTDiscus) were searched, screened, and appraised. Thirteen studies were included in the review. These studies vary greatly in participant recruitment criteria, functional training content, and selection of comparison groups. Mobility exercises were the most common element in functional training across studies. Results show beneficial effects on muscle strength, balance, mobility, and activities of daily living, particularly when the training content was specific to that outcome. Functional training may be used to improve functional performance in older adults.
\end{abstract}

The current study does not involve human or animal subjects.

The first author contributed to the study concepts and design, literature review and appraisal, and manuscript preparation. The second and third authors contributed to literature search, acquisition, and appraisal, as well as manuscript preparation. The fourth author contributed to the manuscript preparation.

C.-j. Liu $(\varangle) \cdot$ D. M. Shiroy $\cdot$ L. Y. Jones

Department of Occupational Therapy, School of Health and Rehabilitation Sciences, Indiana University, 1140 West Michigan

Street, CF 311, Indianapolis, IN 46202-5199, USA

e-mail: liu41@iu.edu

C.-j. Liu • D. O. Clark

Indiana University Center for Aging Research, Indianapolis, IN, USA

\section{O. Clark}

Indiana University School of Medicine, Indianapolis, IN, USA
Keywords Activities of daily living · Disability · Exercise · Functional training $\cdot$ Older adults $\cdot$ Physical functioning

The ability to perform activities of daily living (ADL) is vital to living independently. Age-related loss in muscle strength can jeopardize this ability and lead to disability $[19,25,24,36$, $41,23]$. For example, the progression of muscle weakness limits the ability to grasp an object which further impedes the ability to open a jar. Experiencing difficulty in ADL and relying on others is not only related to decreased quality of life $[39,22]$ but also increased likelihood of long-term nursing home placement [16, 34].

A large number of studies have shown that progressive resistance strength training improves muscle strength in older adults, including the oldest old [15, 48, 32]. Progressive resistance strength training increases load gradually over the training course to strengthen major muscle groups used for weight bearing or lifting. The training has been recommended to prevent or reduce late-life disability for older adults $[2,43]$.

However, improving muscle strength yields only a small change, sometimes even nonsignificant change, in reducing late-life disability in the outcome of ADL [48, 27, 26, 33, 4, $10,29,37]$. For transfer of physical benefits of resistance strength training to ADL performance seems to be limited. It has been suggested that the relationship between muscle strength and physical performance is nonlinear [6]. When the muscle strength has reached a certain threshold, a further increase in muscle strength does not add to better performance, including in older adults with ADL disability [14]. Additionally, older adults may not explicitly learn how to transfer increased muscle strength to improve ADL performance when the training primarily focuses on increasing muscle strength.

Alternatively, functional training may be more beneficial for improving ADL performance in older adults. Functional 
training attempts to train muscles in coordinated, multiplanar movement patterns and incorporates multiple joints, dynamic tasks, and consistent alterations in the base of support for the purpose of improving function $[5,46]$. Boyle defines functional training as purposeful training stating that "function is, essentially, purpose" [6]. Therefore, functional training can be any type of training that is performed with purpose to enhance a certain movement or activity.

With a definition this broad, the literature on functional training has incorporated a vast array of exercise programs with varying designs and focuses. Chin A Paw et al. used game-like and cooperative activities such as throwing and catching a ball as functional training activities [7], while other studies were more focused on exercises simulating locomotor ADL such as walking, stair climbing, or chair stands $[9,17,1,12$, $31,35,47]$. Still, other researchers included modified ADL tasks in the functional training component, such as dressing, laundry, vacuuming, or carrying groceries [12, 35, 11].

The principle of functional training is specificity of training, which means that training in a specific activity is the best way to maximize the performance in that specific activity [20, 42]. In other words, the closer the training is to the desired outcome (i.e., a specific task or performance criterion), the better the outcome will be. Accordingly, in order to improve performance in ADL, exercise training should be performed in similar movement patterns to how people perform daily tasks. Functional training may be a better exercise program for older adults if the aim is to improve independence in ADL.

There is a growing body of literature on functional training in which older adults are trained on specific tasks, such as chair rise or movements needed to carry out daily tasks. A systematic review of these studies would be informative on the design of functional training program and benefits of the training to reduce late-life disability. Therefore, the purpose of this systematic review is to synthesize empirical evidence and assess the effects of functional training in older adults. Although the outcome of ADL is the primary interest of this review, the outcome of muscle strength and physical functioning are also appraised because of strong associations between these measures and disability [19, 24, 36, 40, 38]. In order to narrow the focus of this review, the review limits to functional training as exercises that incorporate movement patterns common to performing ADL.

\section{Methods}

Search strategy

We searched electronic databases of MEDLINE (January 1946 to August 2013), CINAHL (January 1982 to August
2013), and SPORTDiscus (January 1948 to August 2013) with assistance from a university librarian. The following search terms were used: functional training, functional exercise, functional skills, functional task training, and therapeutic exercise. We set the age group to the older adult population, publication type to journal articles, and publication language to English in the database search. We also performed a reverse search by perusing references of eligible articles. Additionally, trial studies referred from colleagues were included for screening and review.

\section{Inclusion and exclusion criteria}

We included randomized controlled trials, nonrandomized trials with two or more groups, and single-group trials with pretest and posttest design. The trial must include functional training as the primary intervention component. Functional training was defined as motions or exercises that incorporate movement patterns which are commonly used in ADL, such as walking, getting out of bed, or dressing. Functional training utilizes a combination of motions rather than isolated movements of individual muscle groups or body function. According to this definition, trials which focused primarily on balance were excluded in this review. Moreover, a trial was excluded from further review if the trial included participants aged less than 60 years; targeted older adults with specific degenerative neurological or musculoskeletal conditions, such as dementia, stroke, and hip replacement; or did not measure outcomes related to physical functioning or ADL performance. Physical functioning measures an individual's physical ability to perform functional tasks, for example balance and gait speed. ADL performance measures an individual's ability to do ADL, for example showering. Both physical functioning and ADL performance can be measured by either performance-based or self-report tests.

\section{Selection and quality assessment}

Two authors screened search results independently. In the initial screening phase, titles and abstracts were reviewed using predefined inclusion and exclusion criteria. If the title and abstract did not provide sufficient information, full text was appraised. In the second screening phase, full text of potential eligible studies was reviewed. When disagreement on the trial eligibility occurred, the two authors would discuss until consensus was reached.

The two authors rated methodological quality of each eligible trial with the Downs and Black rating scale independently [13]. The validity and reliability of the Downs and Black rating scale for randomized and non-randomized studies has been established [13]. The rating scale assesses 
reporting, external validity, internal validity (bias and confounding), and power on 27 questions. The maximum total score for the scale is 32 where a higher score indicates greater methodological quality. The two authors later compared rating results on each question item. If disagreement occurred, the two authors would discuss to reach consensus.

\section{Data extraction}

A standard form was used to extract trial information which included: participant inclusion and exclusion criteria, study design, sample size, the number of dropouts, demographic information, characteristics of the intervention program (i.e., content, duration intensity, and frequency), the adherence rate, and outcome measures of muscle strength, physical functioning, and ADL. Examples of physical functioning outcomes are balance and mobility. One author abstracted information into the standard form and the other author checked it.

\section{Results}

Figure 1 shows the study trial selection process of published studies. The electronic database search yielded 226 records ( 80 from MEDLINE, 92 from CINAHL, and 54 from SPORTDiscus). The authors also included 40 records obtained through reverse search or referred by colleagues. Records were excluded because (1) it was not an intervention trial $(n=$ $65),(2)$ the trial included participants under the age of 60 years $(n=42),(3)$ the trial targeted a specific disease (stroke, $n=47$; hip or knee surgery, $n=9$; dementia or brain injury, $n=9$; critical illness, $n=1$; diabetic neuropathy, $n=1$ ), and (4) functional training was not the primary intervention component $(n=63)$. After screening the full texts and removing duplicates $(n=11)$ and non-English texts $(n=5), 13$ studies were eligible and included for this review.
Study characteristics

Quality assessment Table 1 shows results of methodological quality assessment. The average total score is $21.77(\mathrm{SD}=3.70)$. Four trials have quality scores of less than $20[9,17$, 12, 51]. All of these trials were low in the rating of internal validity because of confounding issues, such as applied a nonrandomization design $[9,12,51]$ or failed to address loss to follow-up [17, 51].

Cohort characteristics Table 2 summarizes participant inclusion and exclusion criteria of the 13 trials that were reviewed. Seven trials recruited older adults aged 70 years or above [17, $12,47,11,8,18,21]$. Three trials recruited older adults from either congregate housing or long-term care facilities $[17,1,31]$. Five studies specifically recruited older adults with some degree of difficulty or dependency in mobility or ADL $[1,31,35,47,18]$. Three trials exclusively recruited women $[9,47,11]$.

Trial characteristics A summary of trial characteristics is presented in Table 3. Four trials enrolled more than 100 participants $[1,31,51,8]$. The adherence rates in two trials were lower than $70 \%[8,21]$. Both included unsupervised home exercise programs.

Both Dobek et al. and Whitehurst et al. used a onegroup research design $[12,51]$. Cress et al. used a twogroup nonrandomization design [9]. Six trials applied a two-group randomized controlled trial design: three trials compared functional training to an attention placebo control group [17, 31, 18]; one trial compared functional training to a control group who engaged in flexibility exercises [1]; one trial compared two programs that differed in functional training dosage, home exercise versus combined home and group exercise [21]; and one trial compared functional training to strength training [28]. Among three trials that applied a three-group
Fig. 1 Flow chart showing selection process of published studies

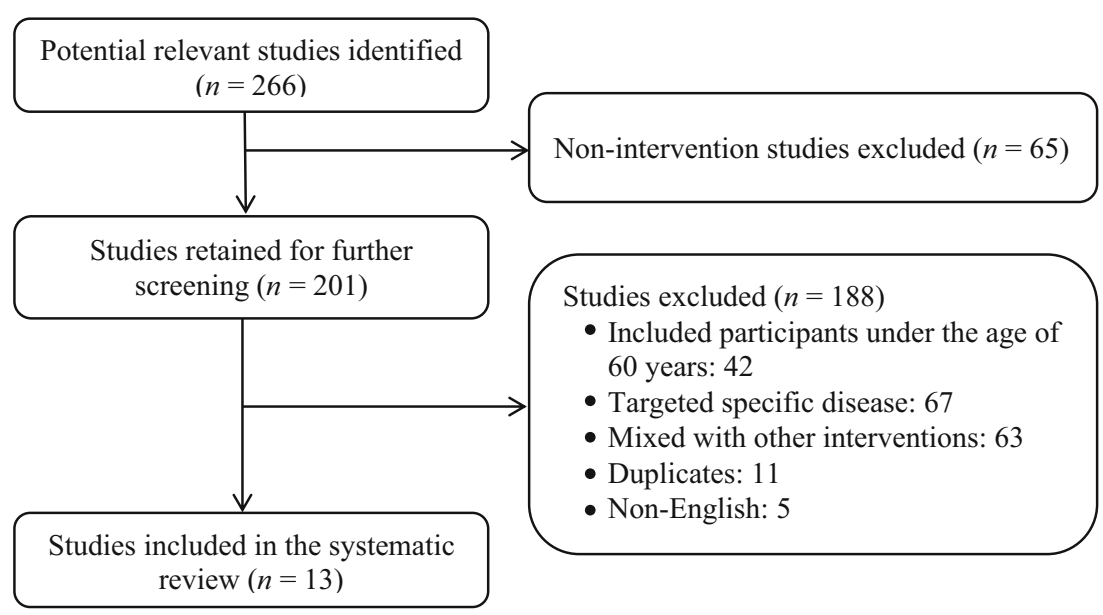


Table 1 Summary of methodological quality assessment scores

The number in parentheses indicates the possible maximum score of each rating category

\begin{tabular}{lllllll}
\hline $\begin{array}{l}\text { Author and publication } \\
\text { year (possible score) }\end{array}$ & $\begin{array}{l}\text { Reporting } \\
(11)\end{array}$ & $\begin{array}{l}\text { External } \\
\text { validity } \\
(3)\end{array}$ & $\begin{array}{l}\text { Internal } \\
\text { validity- } \\
\text { bias (7) }\end{array}$ & $\begin{array}{l}\text { Internal } \\
\text { validity- } \\
\text { confounding (6) }\end{array}$ & $\begin{array}{l}\text { Power } \\
(5)\end{array}$ & $\begin{array}{l}\text { Total } \\
(32)\end{array}$ \\
\hline Alexander et al., 2001 [9] & 11 & 3 & 5 & 3 & 1 & 23 \\
Clemson et al., 2012 [13] & 10 & 2 & 6 & 5 & 1 & 24 \\
Cress et al., 1996 [46] & 8 & 1 & 5 & 3 & 0 & 17 \\
de Vreede et al., 2005 [35] & 11 & 2 & 6 & 3 & 1 & 23 \\
Dobek et al., 2006 [17] & 9 & 0 & 4 & 1 & 1 & 15 \\
Gillies et al., 1999 [7] & 10 & 1 & 4 & 3 & 0 & 18 \\
Giné-Garriga et al., 2010 [51] & 11 & 2 & 5 & 5 & 1 & 24 \\
Helbostad et al., 2004 [8] & 11 & 0 & 6 & 6 & 1 & 24 \\
Krebs et al., 2007 [18] & 11 & 2 & 7 & 5 & 1 & 25 \\
Littbrand et al., 2009 [1] & 11 & 3 & 7 & 6 & 1 & 22 \\
Manini et al., 2007 [12] & 11 & 1 & 4 & 5 & 1 & 22 \\
Skelton et al., 1996 [31] & 10 & 2 & 5 & 4 & 1 & 18 \\
Whitehurst et al., 2005 [38] & 8 & 2 & 5 & 2 & 1 \\
\hline
\end{tabular}

randomized controlled trial design, in addition to a functional training group: two trials included a strength training group [35, 11]; two trials included a control group $[11,8]$; one trial included a strength plus functional training group [35]; and one trial included a strength plus balance training group [8].

Intervention characteristics No two functional training programs were alike. Eight trials included a strength training component $[9,1,31,47,51,8,18,21]$, and five trials included a balance component in functional training $[31,51,8,18,21]$.

The majority of the trials included mobility exercises in functional training. Nine trials included chair stand exercises $[17,1,12,31,35,47,18,21,28]$, seven trials included stair climbing exercises $[9,17,12,31,35,18,21]$, and five trials included walking exercises [17, 31, 47, 18, 21].

Some trials used daily tasks as a medium of training. Two trials had participants practice housework tasks, such as vacuuming, laundry, and carrying groceries $[12,35]$. Clemson et al. had training programs embedded in daily routines [8]. For example, movements that challenge balance and strength were integrated into daily activities, such as ironing with one-leg stand. de Vreede et al. used principles of changing movement directions, speed, and postures within exercise movements required to perform daily tasks, and also used the same principles to practice real daily tasks [11].

The mode of intervention duration is 12 weeks, with the shortest being 6 weeks [28] and the longest being 50 weeks [9]. Duration of each training session usually lasted 45 to $60 \mathrm{~min}$, and frequency was two to three times per week. Four trials used a circuit training format [17, 12, 51, 18]. The exercise intensity could be adjusted according to chair and stair height $[17,1,35,21]$, movement speed $[12,35,11,18,28]$, resistance and weight $[9$, $1,31,47,18,21]$, and the number of repetitions or distance $[17,12]$.

\section{Outcomes of muscle strength, balance, mobility, and ADL}

Muscle strength Nine trials reported outcomes of muscle strength $[9,1,35,47,11,8,18,21,28]$. Six of the nine trials included a strength training component in the functional training program $[9,1,47,8,18,21]$.

When a functional training program which included a strength training component was compared to a control group which received no training or only flexibility exercise, four trials found that functional training significantly increased muscle strength of the lower extremity $[9,1,47,18]$. When a functional training program which included a strength training component was compared to a structured balance and strength training program, Clemson et al. found no group differences [8]. Conversely, when a functional training program which did not include a strength training component was compared to a strength training group, the results favored the strength training group $[35,11]$.

Balance Seven trials reported outcomes of balance $[1,35,47$, $51,8,18,28]$. Three of these trials included a balance training component in the functional training program, and all showed positive results on the balance outcomes $[51,8,18]$. However, the outcomes in functional training programs that did not include a balance training component were mixed. Two trials showed positive results $[1,47]$, while two trials showed negative results $[35,28]$. 
Table 2 Summary of trial inclusion and exclusion criteria and participant characteristics

\begin{tabular}{|c|c|c|c|}
\hline Author and publication year & Inclusion criteria & Exclusion criteria & Living arrangements \\
\hline Alexander et al., 2001 [9] & $\begin{array}{l}65 \text { Years of age or above. Requiring } \\
\text { assistance in transferring, walking, } \\
\text { bathing, and/or toileting. Medically stable. } \\
\text { No evidence of severe dementia or } \\
\text { depression. Not participating in } \\
\text { regular, strenuous exercise. }\end{array}$ & NS & Congregate housing residents \\
\hline Clemson et al., 2012 [13] & $\begin{array}{l}70 \text { Years of age or above. Had } 2 \text { or } \\
\text { more falls in the past } 12 \text { months. }\end{array}$ & $\begin{array}{l}\text { Moderate to severe cognitive problems. } \\
\text { No conversational English. Inability to } \\
\text { ambulate Independently. Neurological } \\
\text { conditions that severely influenced } \\
\text { gait and mobility. Resident in a nursing } \\
\text { home or hostel. Having any unstable or } \\
\text { terminal illness. }\end{array}$ & $\begin{array}{l}\text { Recruited from the Department } \\
\text { of Veterans Affairs and } \\
\text { general practices databases. }\end{array}$ \\
\hline Cress et al., 1996 [46] & $\begin{array}{l}\text { Women from } 65 \text { years to } 83 \text { years } \\
\text { of age. No known cardiovascular, } \\
\text { neuromuscular, or metabolic disease. }\end{array}$ & NS. & $\begin{array}{l}\text { Healthy community dwelling } \\
\text { older women. }\end{array}$ \\
\hline de Vreede et al., 2005 [35] & $\begin{array}{l}\text { Women } 70 \text { years of age or above. } \\
\text { Medically fit to participate in } \\
\text { an exercise program. }\end{array}$ & $\begin{array}{l}\text { Recent fractures, unstable cardiovascular } \\
\text { or metabolic diseases, musculoskeletal } \\
\text { disease or other chronic illnesses, } \\
\text { severe airflow obstruction, recent } \\
\text { depression or emotional distress, or } \\
\text { loss of mobility for more than } 1 \text { week } \\
\text { in the last } 2 \text { months. Respondents } \\
\text { who exercised } 3 \text { times a week or } \\
\text { more at a sports club. }\end{array}$ & Community dwelling. \\
\hline Dobek et al., 2006 [17] & $\begin{array}{l}70 \text { Years of age or above. Being } \\
\text { ambulatory. }\end{array}$ & $\begin{array}{l}\text { Unable to follow directions or complete } \\
\text { baseline testing. }\end{array}$ & Community dwelling. \\
\hline Gillies et al., 1999 [7] & $\begin{array}{l}70 \text { years of age or above. Being mobile and } \\
\text { able to perform test battery. No medical } \\
\text { conditions which would interfere with the } \\
\text { safe conduct of the training exercise. }\end{array}$ & NS. & $\begin{array}{l}\text { Recruited from two residential } \\
\text { homes. }\end{array}$ \\
\hline $\begin{array}{l}\text { Giné-Garriga et al., } 2010 \\
\text { [51] }\end{array}$ & $\begin{array}{l}\text { Between } 80 \text { and } 90 \text { years of age. } \\
\text { Had some or a lot of difficulty } \\
\text { rising from a chair or climbing a } \\
\text { flight. Being physically frail. }\end{array}$ & $\begin{array}{l}\text { Unable to walk. Undergoing an exercise } \\
\text { program. Had severe dementia. Had } \\
\text { stroke, hip fracture, myocardial } \\
\text { infarction, or hip- or knee- replacement } \\
\text { surgery within the previous } 6 \text { months. }\end{array}$ & $\begin{array}{l}\text { Recruited from one health } \\
\text { care center. }\end{array}$ \\
\hline Helbostad et al., 2004 [8] & $\begin{array}{l}75 \text { Years of age or above. Either } \\
\text { suffered one or more falls during } \\
\text { the last year, or use some kind } \\
\text { of walking aid. }\end{array}$ & $\begin{array}{l}\text { Participating in regular exercise more } \\
\text { than once a week, terminal illness, } \\
\text { cognitive impairment as indicated } \\
\text { by a score of }<22 \text { on the MMSE, } \\
\text { stroke during the last } 6 \text { months, } \\
\text { or were deemed unable to tolerate } \\
\text { exercise by a geriatrician. }\end{array}$ & $\begin{array}{l}\text { Frail community dwelling } \\
\text { older adults. }\end{array}$ \\
\hline Krebs et al., 2007 [18] & $\begin{array}{l}60 \text { Years of age or above. No cognitive } \\
\text { impairments. Being able to ambulate } \\
\text { for } 15 \mathrm{ft} \text {. }\end{array}$ & $\begin{array}{l}\text { Terminal illness, progressive neurological } \\
\text { disease, major loss of vision, acute } \\
\text { pain, non-ambulatory status. }\end{array}$ & $\begin{array}{l}\text { Recruited through weekly } \\
\text { screening of the outpatient } \\
\text { physical therapy } \\
\text { appointments. }\end{array}$ \\
\hline Littbrand et al., 2009 [1] & $\begin{array}{l}65 \text { Years of age or above. Dependent on one } \\
\text { or more activities of daily living. Ability to } \\
\text { stand up from a chair with assistance. } \\
\text { MMSE scored } 10 \text { or higher. Having } \\
\text { physician's approval. }\end{array}$ & NS. & $\begin{array}{l}\text { Residential care facilities. } \\
\text { High percentage of } \\
\text { participants had a diagnosis } \\
\text { of dementia. }\end{array}$ \\
\hline Manini et al., 2007 [12] & $\begin{array}{l}\text { Having difficulty to rise from a } \\
\text { chair or climb a flight of stairs. }\end{array}$ & NS. & $\begin{array}{l}\text { Recruited from community } \\
\text { senior centers. }\end{array}$ \\
\hline Skelton et al., 1996 [31] & $\begin{array}{l}\text { Women } 74 \text { years of age or above. } \\
\text { Having functional or mobility } \\
\text { difficulties. }\end{array}$ & $\begin{array}{l}\text { Disease or condition that would be } \\
\text { adversely affected by exercise. }\end{array}$ & $\begin{array}{l}\text { Patients of a local general } \\
\text { medical practice. }\end{array}$ \\
\hline Whitehurst et al., 2005 [38] & Older adults. & Did not pass medical clearance. & Community-dwelling \\
\hline
\end{tabular}

MMSE Mini-Mental State Examination, NS not specified 


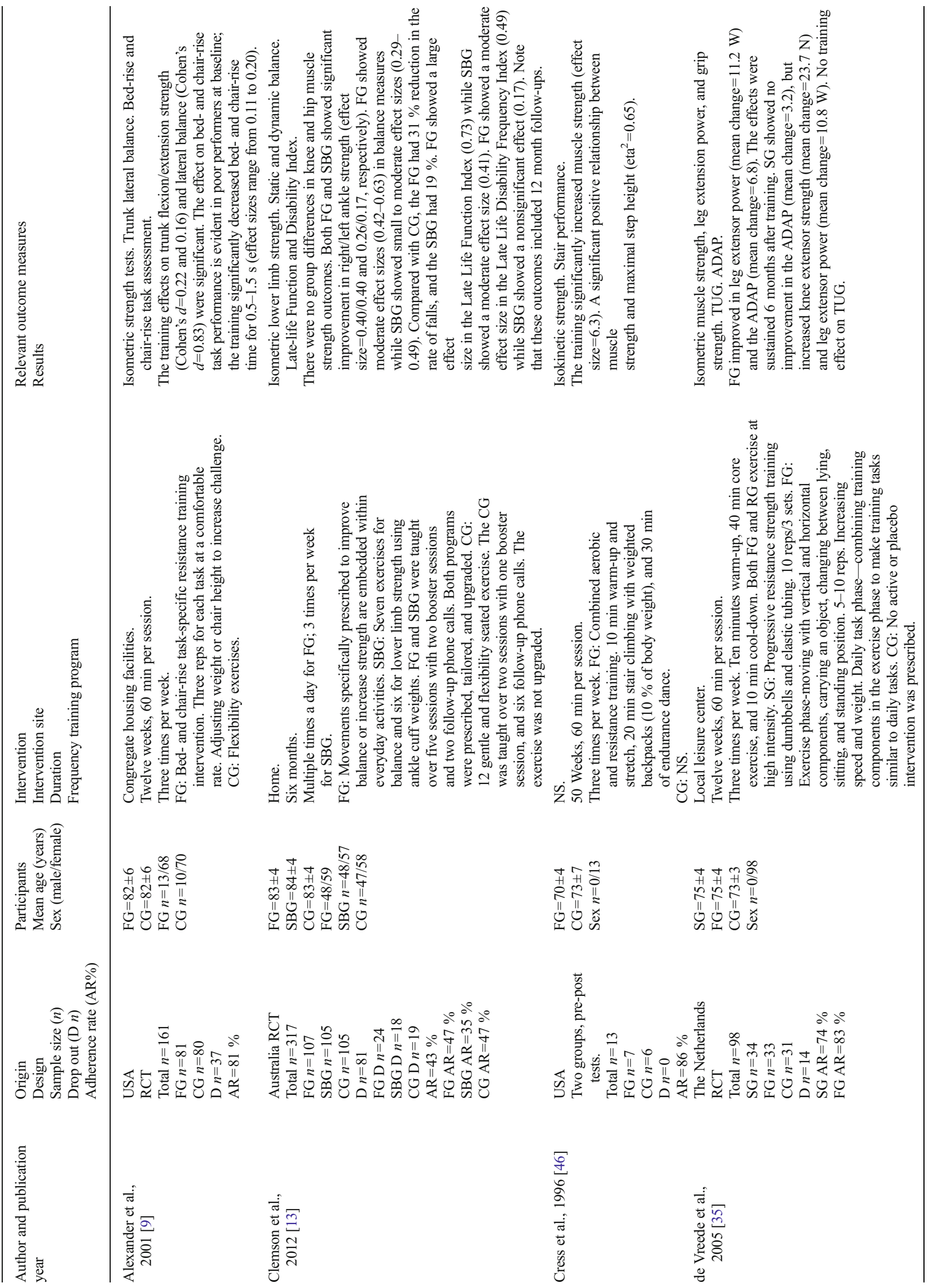




\begin{tabular}{|c|c|c|c|c|}
\hline 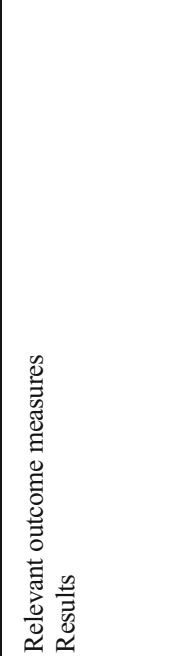 & 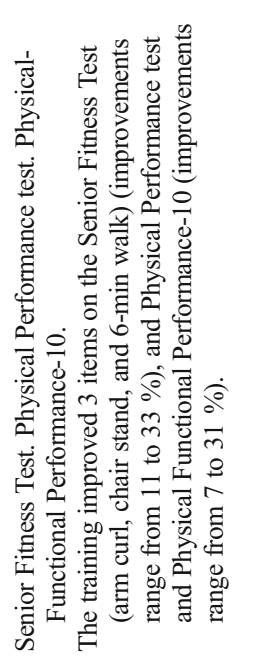 & 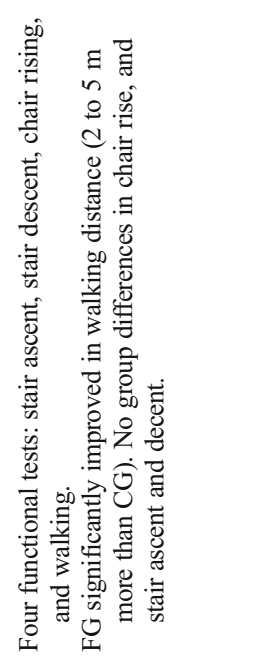 & 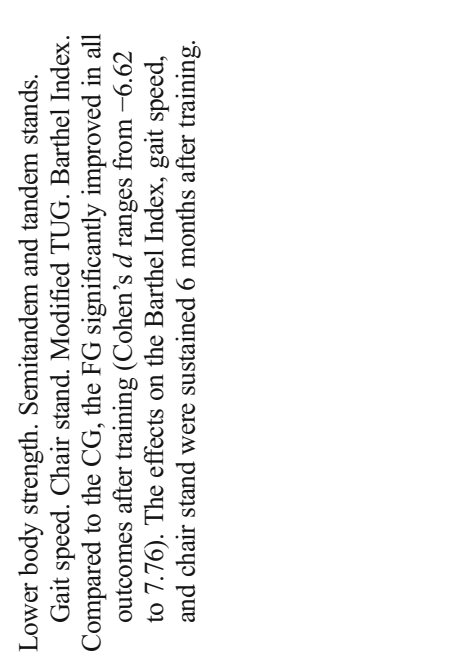 & 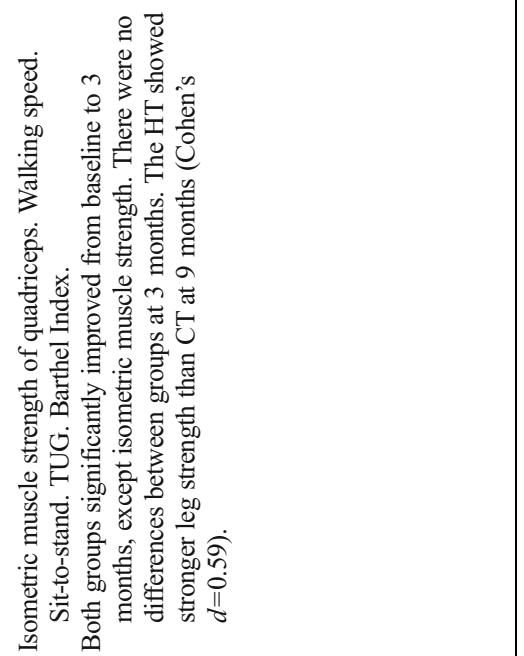 \\
\hline 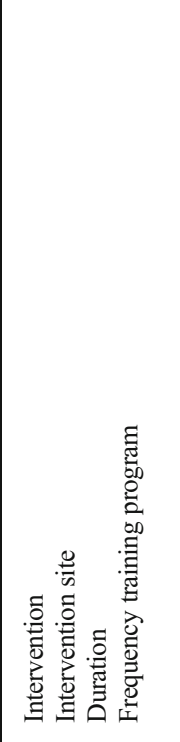 & 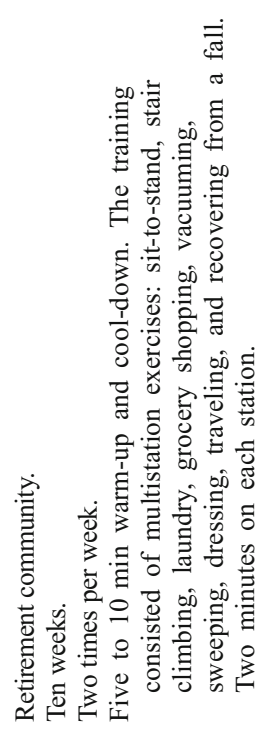 & 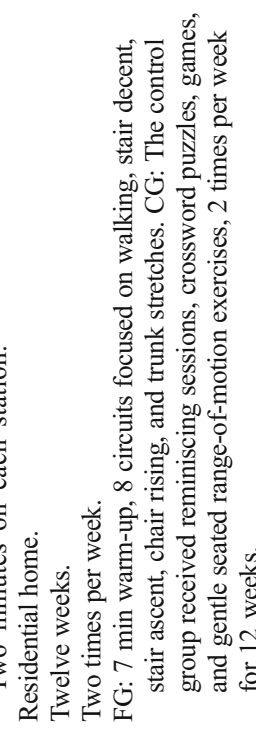 & 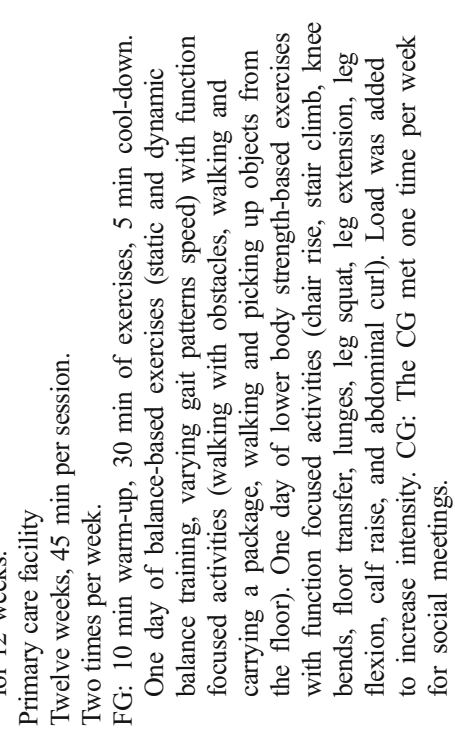 & 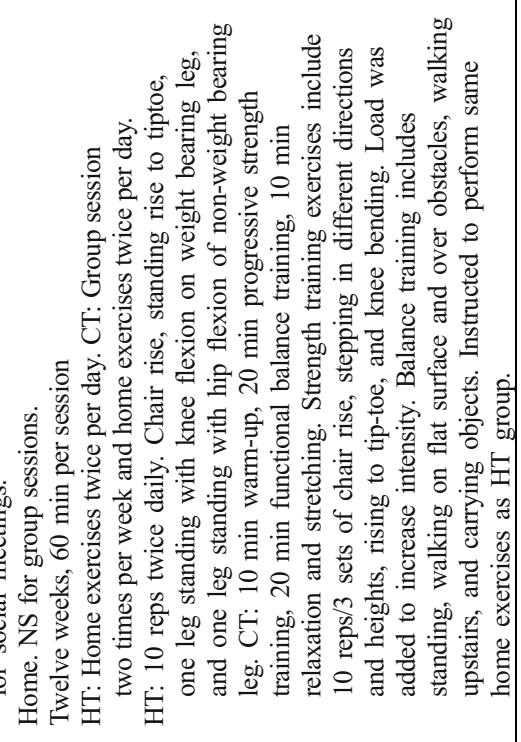 \\
\hline 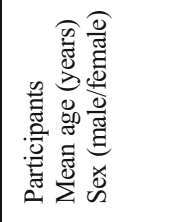 & 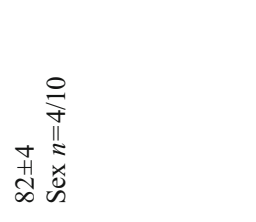 & 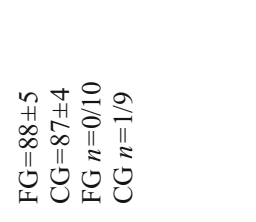 & 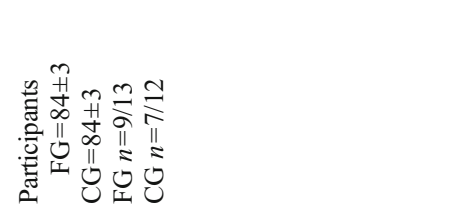 & 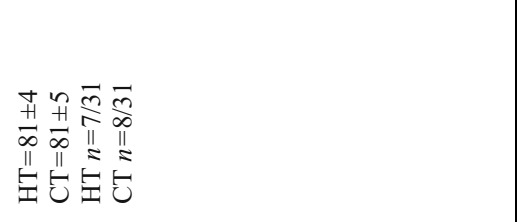 \\
\hline 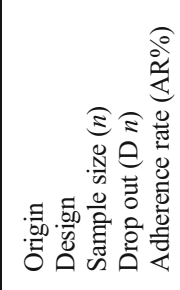 & 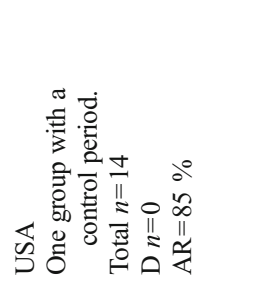 & 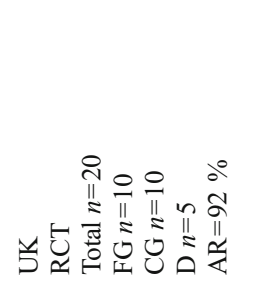 & 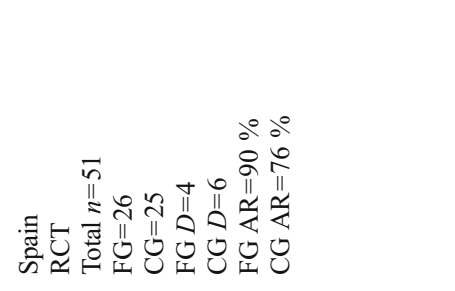 & 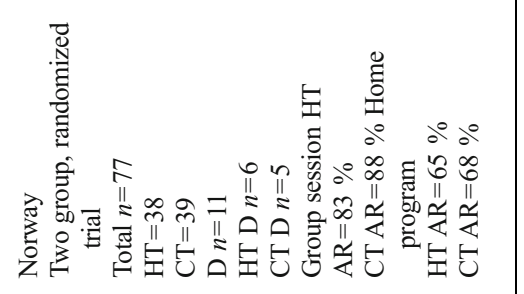 \\
\hline $\begin{array}{l}\overline{7} \\
\bar{z} \\
\bar{\Xi} \\
\bar{\Xi}\end{array}$ & 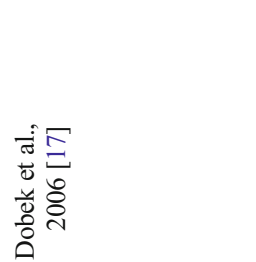 & 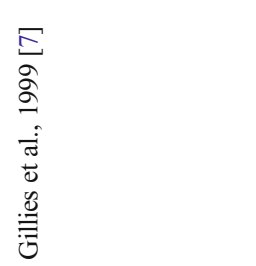 & 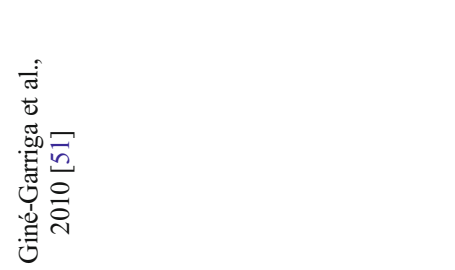 & 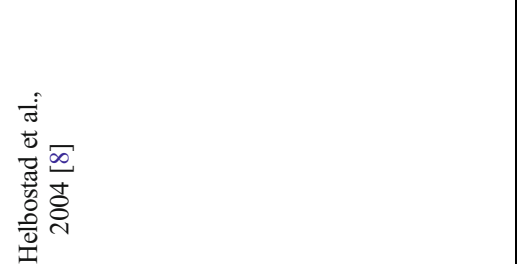 \\
\hline
\end{tabular}




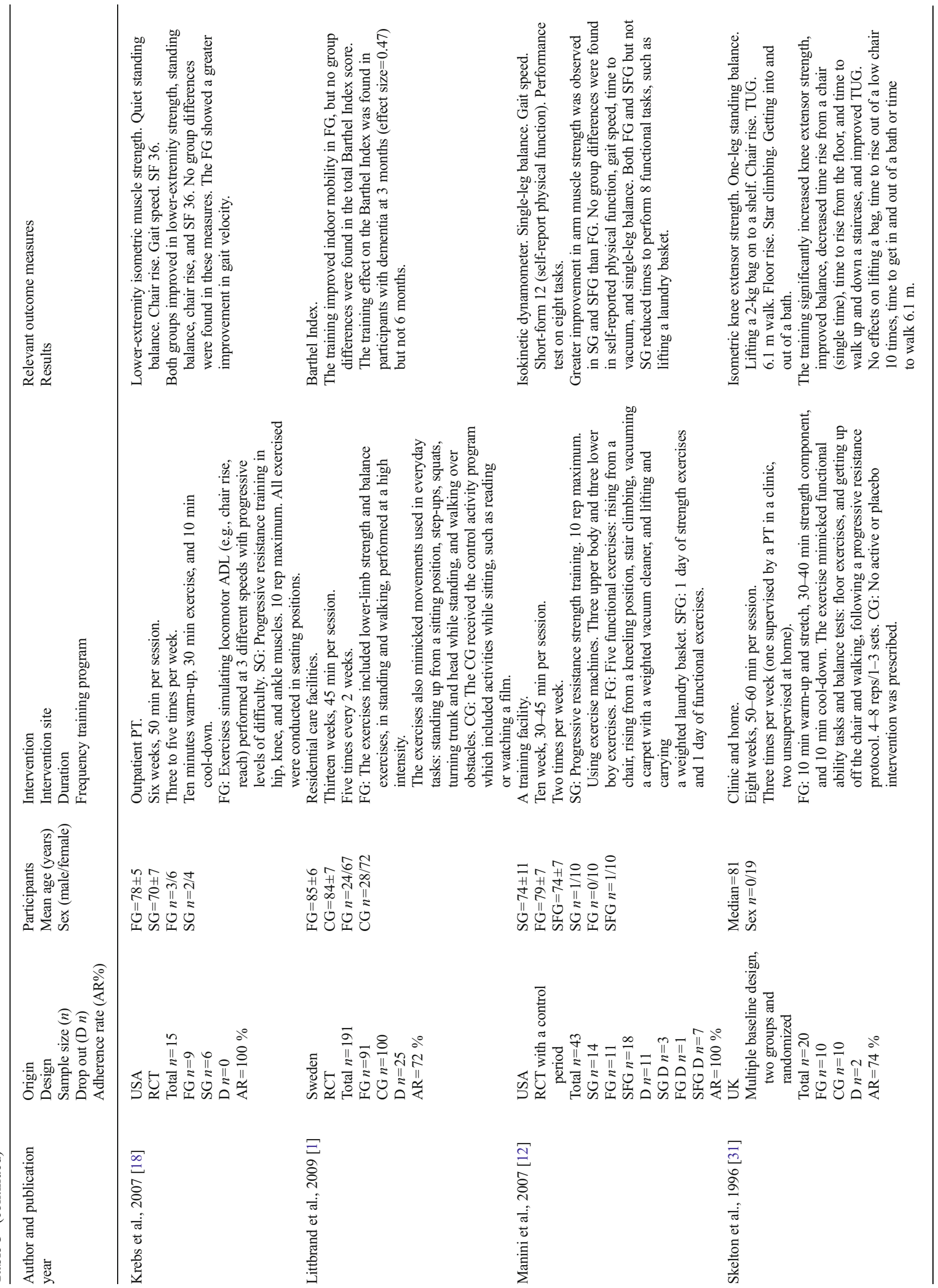


Mobility Twelve trials reported outcomes of mobility $[9,17$, $1,12,35,47,11,51,8,18,21,28]$. Seven trials included chair stand exercises in functional training and reported related physical measurement outcomes. Five trials found functional training improved chair stand results $[1,12,47,18,21]$ while the other two found no superior effects of functional training $[17,28]$.

Although several studies included stair climbing in functional training, only two reported related physical measurement outcomes. Cress et al. found improved performance in healthy elder women [9] whereas Gillies et al. found no improvement in long-term care residents [17]. Five trials used the Timed Up and Go test or a modified Timed Up and Go test $[47,11,51,18,21]$. Four trials found positive results when compared to the baseline or to a comparison group $[47,51,18$, 21].

Seven trials measured walking performance which includes timed walking or walking speed $[17,12,35,47,18$, 21, 28]. Five trials showed improvement either in walking distance $[17,12]$ or walking speed $[18,21,28]$. Additionally, Littbrand et al. found that functional training increased indoor mobility when compared to strength training alone [31]. Clemson et al. found that ADL embedded functional training significantly reduced falls compared to structured strength and balance exercise [8].

$A D L$ Seven trials reported outcomes of ADL $[12,31,35,11$, $8,18,21]$. The Barthel Index was used in three trials [31, 18, 21]. Two trials found positive results of functional training $[18,21]$. One trial did not find a group difference but the effect was prominent in participants with dementia [31]. The other four trials found positive results either on self-report tests [8] or on task performance tests $[12,35,11]$. Moreover, three trials compared functional training and structured muscle strength training $[35,11,8]$, and found favorable results of functional training on the ADL outcome.

Five trials reported long-term effects of functional training on ADL $[31,11,8,18,21]$. Three trials identified that the training effect was sustained after 6 months when compared to strength training [35] or attention controls [8, 18]. Two trials did not show the long-term effect. One trial compared homebased functional training to combined format of group and home-based functional training [21]. The other trial compared functional training to attention controls and is the only trial among the seven that was conducted in residential care facilities [31].

\section{Discussion}

This systematic review included 13 trials with 1,139 participants to evaluate the effects of functional training on muscle 
strength, physical functioning, and ADL in older adults. The intervention must include motions or exercises that use movement patterns similar to performing daily tasks to be considered as functional training in the review. Reviewed trials have incorporated a strength component, a balance component, mobility tasks, or daily tasks in functional training. Although functional training content varied greatly in these trials, mobility exercises were the most common element in functional training across trials. Most training programs were 12 weeks, two or three times per week, and 45 to $60 \mathrm{~min}$ per session.

The review identified positive effects of functional training. The effects are in accord with the specificity of training principle $[20,42]$. When the functional training program includes the element of strength training, the training improves the outcome of muscle strength $[9,1,47,8,18]$. Similarly, when the training program includes the element of balance, the training improves the outcome of balance $[51,8$, 18]. When the training program includes the element of chair standing, the training reduces time in standing up from a chair or improves chair standing performance $[1,12,47,18,21]$. When the training program includes the element of practicing actual daily life tasks, the training improves the outcome of ADL $[12,35,11,8]$.

The goal of functional training is to optimize competence of an individual to do a certain task [45]. Both simple daily tasks, such as getting up from a chair, and complex daily tasks, such as vacuuming, require cooperation between multiple muscle groups and body motor elements in order to carry out the task. Depending on the task demand, some motor elements of the body may be more essential than others. For example, Fig. 2 illustrates the possible body elements required

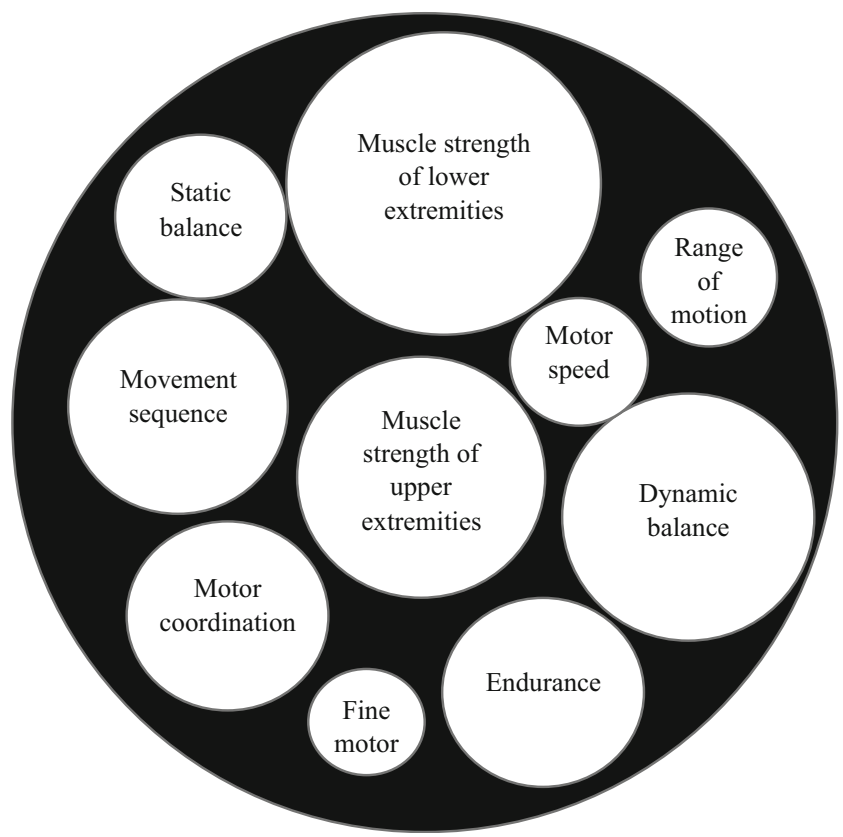

Fig. 2 Illustration of possible body motor elements required to vacuum a room to vacuum a room. Each element required to perform the vacuuming task is represented by a circle. Although all elements are necessary to successfully vacuum a room, these more essential elements are represented by larger circles in the figure.

Functional training designed to improve an individual's ability to perform a certain daily task can target either these essential elements (element-based functional training) or all elements (task-specific-based functional training). We have observed both element-based functional training and taskspecific-based functional training in this review. An example of element-based functional training is performing exercises such as step-ups or squats to improve lower extremity strength [31]. An example of task-specific-based functional training is combining functional movements with weight or speed, such as practicing chair rising while wearing a weighted vest [47] or practicing chair rising at difference speeds [28]. We have also observed combination of the two (hybrid functional training) - performing daily tasks in a slightly challenging way in order to practice the elements, such as practicing balance while washing dishes with a tandem stand [8]. We cannot conclude which type of functional training is the most effective from this review because each reviewed study differs in participant recruitment criteria, selection of comparison groups, and target functional tasks. Moreover, it is unclear whether element or task-specific training is most effective, as it may differ by the activity (e.g., stair climbing versus dressing). Further research is needed to compare these two types of functional training.

An element-based functional training may be similar to a multicomponent intervention which has been examined in the literature of late-life disability prevention [3, 30, 49]. A multicomponent intervention program includes several elements, usually muscle strength, balance, flexibility, and endurance, to improve physical capacity and to prevent functional decline in older adults. Multicomponent exercise is the most common exercise protocol for frail older adults [50]. Both elementbased functional training and multicomponent interventions work on the fundamental elements through structured exercises. A multicomponent intervention could be considered functional training if the training includes purposeful movements or activities, according to our definition. Nearly half of the trials included in this review applied functional training that included balance component and strength training component $[31,47,51,8,18,21]$. There is moderate evidence in this review showing that functional training includes multicomponents improves physical functioning.

Three trials yield a consistent and conversing result showing that functional training is more effective than structured strength training alone on improving $\operatorname{ADL}[12,35,13]$. Two of these trials show that such effect can be sustained for 6 months [11, 8]. Although age-related decline in muscle strength is strongly related to functional decline in older adults 
$[19,25,24,36,41,23]$, the process of aging also influences other motor elements that are essential for ADL performance such as coordination [44]. If the training only targets one essential body motor element and ignore other elements, the training effect on ADL may be compromised. Conversely, functional training facilitates multiple muscles and body motor elements acting together which is more approximate to the way people perform an ADL. The finding also supports the specificity of training principle.

A limitation of this review is that some trials might have been missed by the search terms despite the intervention fitting within the concept of functional training. Another limitation is that meta-analysis could not be conducted because heterogeneous training content, participant selections, comparison groups, and outcome measures exist among study trials. However, this review shed some light on the potential for functional training to reduce late-life ADL disability and the loss of independence.

\section{Conclusion}

We appraised 13 trials of functional training in this review and the results support the specificity of training principle; that is, the best gains in performance are achieved when the training closely mimics the performance. Therefore, functional training may be a better option than muscle strength training alone if the goal is to reduce ADL disability in older adults. Moreover, reviewed trials show a great difference in research design, participant recruitment criteria, and functional training programs. We identified three patterns of functional training: element-based functional training, task-specific-based functional training, and hybrid functional training. Additional research to examine the effect of functional training according to the three patterns on reducing functional decline in older adults is encouraged.

Conflict of interest All the authors declare no conflict of interest.

\section{References}

1. Alexander NB, Galecki AT, Grenier ML, Nyquist LV, Hofmeyer MR, Grunawalt JC et al (2001) Task specific resistance training to improve the ability of activities of daily living - impaired older adults to rise from a bed and from a chair. J Am Geriatr Soc 49:1418-1427

2. Bean JF, Vora A, Frontera WR (2004) Benefits of exercise for community-dwelling older adults. Arch Phys Med Rehabil 85:S31S42

3. Bird M, Hill KD, Ball M, Hetherington S, Williams AD (2011) The long-term benefits of a multi-component exercise intervention to balance and mobility in healthy older adults. Arch Gerontol Geriatr $52: 211-216$
4. Boshuizen HC, Stemmerik L, Westhoff MH, Hopman-Rock M (2005) The effects of physical therapists' guidance on improvement in a strength-training program for the frail elderly. J Aging Phys Act 13:5-22

5. Boyle M (2004) Functional training for sports. Human Kinetics, Champaign, IL

6. Buchner DM, Larson EB, Wagner EH, Koepsell TD, De Lateur BJ (1996) Evidence for a non-linear relationship between leg strength and gait speed. Age Ageing 25:386-391

7. Chin A, Paw MJM, van Poppel MNM, Twisk JWR, van Mechelen W (2006) Once a week not enough, twice a week not feasible? A randomised controlled exercise trial in long-term care facilities [ISRCTN87177281]. Patient Educ Couns 63:205-214

8. Clemson L, Singh MAF, Bundy A, Cumming RG, Manollaras K, O' Loughlin $\mathrm{P}$ et al (2012) Integration of balance and strength training into daily life activity to reduce rate of falls in older people (the LiFE study): randomised parallel trial. Br Med J 345:14

9. Cress M, Conley K, Balding S, Hansen-Smith F, Konczak J (1996) Functional training: muscle structure, function, and performance in older women. J Orthop Sports Phys Ther 24:4-10

10. Damush TM, Damush JG Jr (1999) The effects of strength training on strength and health-related quality of life in older adult women. Gerontologist 39:705-710

11. de Vreede PL, Samson MM, van Meeteren NLU, Duursma SA, Verhaar HJJ (2005) Functional task exercise versus resistance strength exercise to improve daily function in older women: a randomized, controlled trial. J Am Geriatr Soc 53:2-10

12. Dobek J, White K, Gunter K (2007) The effect of a novel ADL-based training program on performance of activities of daily living and physical fitness. J Aging Phys Act 15:13-25

13. Downs SH, Black N (1998) The feasibility of creating a checklist for the assessment of the methodological quality both of randomised and non-randomised studies of health care interventions. J Epidemiol Community Health 52:377-384

14. Ferrucci L, Guralnik JM, Buchner D, Kasper J, Lamb SE, Simonsick EM et al (1997) Departures from linearity in the relationship between measures of muscular strength and physical performance of the lower extremities: the Women's Health and Aging Study. J Gerontol A: Biol Med Sci 52:M275-M285

15. Fiatarone MA, O'Neill EF, Ryan ND, Clements KM, Solares GR, Nelson ME et al (1994) Exercise training and nutritional supplementation for physical frailty in very elderly people. N Engl J Med 330: $1769-1775$

16. Gaugler J, Duval S, Anderson K, Kane R (2007) Predicting nursing home admission in the US: a meta-analysis. BMC Geriatr 7:13

17. Gillies E, Aitchison T, MacDonald J, Grant S (1999) Outcomes of a 12-week functional exercise programme for institutionalised elderly people. Physiotherapy 85:349-357

18. Giné-Garriga M, Guerra M, Pagès E, Manini TM, Jiménez R, Unnithan VB (2010) The effect of functional circuit training on physical frailty in frail older adults: a randomized controlled trial. J Aging Phys Act 18:401-424

19. Hairi NN, Cumming RG, Naganathan V, Handelsman DJ, Le Couteur DG, Creasey H et al (2010) Loss of muscle strength, mass (sarcopenia), and quality (specific force) and its relationship with functional limitation and physical disability: The Concord Health and Ageing in Men project. J Am Geriatr Soc 58:2055-2062

20. Hawley JA (2008) Specificity of training adaptation: time for a rethink? J Physiol 586:1-2

21. Helbostad JL, Sletvold O, Moe-Nilssen R (2004) Effects of home exercises and group training on functional abilities in home-dwelling older persons with mobility and balance problems. A randomized study. Aging Clin Exp Res 16:113-121

22. Hellström Y, Persson G, Hallberg IR (2004) Quality of life and symptoms among older people living at home. J Adv Nurs 48:584 593 
23. Hughes VA, Frontera WR, Wood M, Evans WJ, Dallal GE, Roubenoff $\mathrm{R}$ et al (2001) Longitudinal muscle strength changes in older adults: influence of muscle mass, physical activity, and health. J Gerontol 56A:209-217

24. Janssen I, Heymsfield SB, Ross R (2002) Low relative skeletal muscle mass (sarcopenia) in older persons is associated with functional impairment and physical disability. J Am Geriatr Soc 50:889-896

25. Jette AM, Branch LG, Berlin J (1990) Musculoskeletal impairments and physical disablement among the aged. J Gerontol 45:M203M208

26. Keysor JJ (2003) Does late-life physical activity or exercise prevent or minimize disablement? A critical review of the scientific evidence. Am J Prev Med 25:129-136

27. Keysor JJ, Jette AM (2001) Have we oversold the benefit of late-life exercise? J Gerontol 56:M412-M423

28. Krebs DE, Scarborough DM, McGibbon CA (2007) Functional vs. strength training in disabled elderly outpatients. Am J Phys Med Rehabil 86:93-103

29. Latham NK, Anderson CS, Lee A, Bennett DA, Moseley A, Cameron ID et al (2003) A randomized, controlled trial of quadriceps resistance exercise and vitamin D in frail older people: the Frailty Interventions Trial in Elderly Subjects (FITNESS). J Am Geriatr Soc 51:291-299

30. Levy SS, Macera CA, Hootman JM, Coleman KJ, Lopez R, Nichols JF et al (2012) Evaluation of a multi-component group exercise program for adults with arthritis: Fitness and Exercise for People with Arthritis (FEPA). Disabil Health J 5:305-311

31. Littbrand H, Lundin Olsson L, Gustafson Y, Rosendahl E (2009) The effect of a high intensity functional exercise program on activities of daily living: a randomized controlled trial in residential care facilities. J Am Geriatr Soc 57:1741-1749

32. Liu C-J, Latham NK (2009) Progressive resistance strength training for improving physical function in older adults. Cochrane Database Syst Rev. DOI: 10.1002/14651858.CD002759.pub2.

33. Liu C-J, Latham N (2011) Can progressive resistance strength training reduce physical disability in older adults? A meta-analysis study. Disabil Rehabil 33:87-97

34. Luppa M, Luck T, Weyerer S, König H-H, Brähler E, Riedel-Heller SG (2010) Prediction of institutionalization in the elderly. A systematic review. Age Ageing 39:31-38

35. Manini T, Marko M, VanArnam T, Cook S, Fernhall B, Burke J et al (2007) Efficacy of resistance and task-specific exercise in older adults who modify tasks of everyday life. J Gerontol 62:M616-M623

36. McGee CW, Mathiowetz V (2003) The relationship between upper extremity strength and instrumental activities of daily living performance among elderly women. OTJR: Occupation, Participation, and Health 23:143-154
37. McMurdo MET, Johnstone R (1995) A randomized controlled trial of a home exercise programme for elderly people with poor mobility. Age Ageing 24:425-428

38. Onder G, Penninx BWJH, Ferrucci L, Fried LP, Guralnik JM, Pahor M (2005) Measures of physical performance and risk for progressive and catastrophic disability: results from the women's health and aging study. J Gerontol A: Biol Med Sci 60:74-79

39. Oswald F, Wahl H-W, Schilling O, Nygren C, Fänge A, Sixsmith A et al (2007) Relationships between housing and healthy aging in very old age. Gerontologist 47:96-107

40. Puthoff ML, Nielsen DH (2007) Relationships among impairments in lower-extremity strength and power, functional limitations, and disability in older adults. Phys Ther 87:1334-1347

41. Rantanen T, Guralnik J, Sakari-Rantala R, Leveille S, Simonsick E, Ling S et al (1999) Disability, physical activity, and muscle strength in older women: the women's health and aging study. Arch Phys Med Rehabil 80:130-135

42. Reilly T, Morris T, Whyte G (2009) The specificity of training prescription and physiological assessment: a review. J Sports Sci 27:575-589

43. Seguin R, Nelson ME (2003) The benefits of strength training for older adults. Am J Prev Med 25:141-149

44. Seidler RD, Bernard JA, Burutolu TB, Fling BW, Gordon MT, Gwin JT et al (2010) Motor control and aging: Links to age-related brain structural, functional, and biochemical effects. Neurosci Biobehav Rev 34:721-733

45. Siff MC (2002) Functional training revisited. Strength Cond J 24:4249

46. Sipe C, Ritchie D (2012) The significant 7 principles of functional training for mature adults. IDEA Fitness Journal 9:42-49

47. Skelton DA, McLaughlin AW (1996) Training functional ability in old age. Physiotherapy 82:159-167

48. Skelton DA, Young A, Greig CA, Malbut KE (1995) Effects of resistance training on strength, power, and functional abilities of women aged 75 and older. J Am Geriatr Soc 43:1081-1087

49. Taguchi N, Higaki Y, Inoue S, Kimura H, Tanaka K (2010) Effects of a 12-month multicomponent exercise program on physical performance, daily physical activity, and quality of life in very elderly people with minor disabilities: an intervention study. J Epidemiol 20:21-29

50. Theou O, Stathokostas L, Roland KP, Jakobi JM, Patterson C, Vandervoort AA, et al. The effectiveness of exercise interventions for the management of frailty: a systematic review. J Aging Res. DOI: $10.4061 / 2011 / 569194$.

51. Whitehurst MA, Johnson BL, Parker CM, Brown LE, Ford AM (2005) The benefits of a functional exercise circuit for older adults. J Strength Cond Res 19:647-651 